ISSN 0103-9954

\title{
RELAÇÃO SOLO/PAISAGEM E SUA VARIAÇÃO TEMPORAL EM UMA ESTAÇÃO EXPERIMENTAL DE SILVICULTURA
}

\author{
SOIL-LANDSCAPE RELATIONSHIP AND ITS TEMPORAL VARIATION IN A FORESTRY \\ EXPERIMENTAL STATION
}

\begin{abstract}
Júlio Cesar Wincher Soares ${ }^{1}$ Dalvan José Reinert ${ }^{2}$ José Miguel Reichert ${ }^{3}$ Douglas Rodrigo Kaiser ${ }^{4}$ Jean Paolo Gomes Minella ${ }^{5}$ Adriano Dicesar Martins de Araujo Gonçalves ${ }^{6}$ Telmo Almansa Silva ${ }^{7}$ Tatiane Almeida Netto ${ }^{8}$ Vagner Carzola Bressan ${ }^{9}$
\end{abstract}

\section{RESUMO}

A caracterização de componentes da paisagem e de suas relações na Estação Experimental de Silvicultura de Santa Maria - RS e o monitoramento da variação temporal solo/paisagem entre os anos de 1987 e 2009 (22 anos) foram realizados, por meio de levantamentos de campo e mapeamento digital da cobertura vegetal, relevo e solos. Cruzaram-se informações do histórico de uso e ocupação do solo, de transecções realizadas em 2009, do modelo numérico do terreno, de mapas de cobertura vegetal para 1987 e 2009 e de solos. Derivou-se assim um caráter transitório dos componentes da paisagem, entre o Rebordo do Planalto Sul-Riograndense e a Depressão Central do Rio Grande do Sul, com uma descaracterização das fitofisionomias naturais e existência de conflitos de uso do solo, bem como a influência do relevo e da gênese dos solos sobre o desenvolvimento fitofisionômico. Houve expansão, em 22 anos, dos cultivos de Eucalyptus e Pinus, e da floresta nativa sobre o campo antrópico, principalmente em áreas com Argissolos Bruno-Acinzentados e Argissolos Vermelhos.

Palavras-chave: componentes da paisagem; geoprocessamento; variação temporal.

\section{ABSTRACT}

The characterization of landscape components and their relationships for the Forestry Experimental Station of Santa Maria,Rio Grande do Sul state, Brazil, and the monitoring of soil-landscape temporal variation between the years 1987 and 2009 (22 years) were performed by means of field surveys and digital

1 Engenheiro Florestal, MSc., Doutorando pelo Programa de Pós-graduação em Engenharia Florestal, Centro de Ciências Rurais, Universidade Federal de Santa Maria, Av. Roraima, 1000, CEP 97105-900, Santa Maria (RS), Brasil.juliowincher@gmail.com

2 Engenheiro Agrônomo, Dr., Professor Titular do Departamento de Solos, Centro de Ciências Rurais, Universidade Federal de Santa Maria, Av. Roraima, 1000, CEP 97105-900, Santa Maria (RS), Brasil. dalvan@ccr.ufsm.br

3 Engenheiro Agrônomo, Dr., Professor Titular do Departamento de Solos, Centro de Ciências Rurais, Universidade Federal de Santa Maria, Av. Roraima, 1000, CEP 97105-900, Santa Maria (RS), Brasil. reichert@ufsm.br

4 Engenheiro Agrônomo, Dr., Professor do Departamento de Solos, Universidade Federal da Fronteira Sul, Rua Major Antônio Cardoso, 590, CEP 97900-000, Cerro Largo (RS), Brasil. douglasrodrigokaiser@gmail.com

5 Engenheiro Agrônomo, Dr., Professor do Departamento de Solos, Centro de Ciências Rurais, Universidade Federal de Santa Maria, Av. Roraima, 1000, CEP 97105-900, Santa Maria (RS), Brasil. jminella@smail.ufsm.br

6 Engenheiro Agrícola, Pós-doutorando pelo Programa de Pós-graduação em Engenharia Florestal, Centro de Ciências Rurais, Universidade Federal de Santa Maria, Av. Roraima, 1000, CEP 97105-900, Santa Maria (RS), Brasil.almansaflorestal@hotmail.com

7 Engenheiro Florestal, MSc., Empresa Santa Maria Consultoria Florestal Ltda., Rod. BR 158, 260, Bloco A3, Apto. 208, Bairro Pinheiro Machado, CEP 97030-620, Santa Maria (RS), Brasil.

8 Engenheira Florestal, Doutoranda pelo Programa de Pós-graduação em Geografia e Geociências, Centro de Ciências Naturais e Exatas, Universidade Federal de Santa Maria, Av. Roraima, 1000, CEP 97105-900, Santa Maria (RS), Brasil. tatianetto@gmail.com

9 Engenheiro Ambiental, Centro Universitário Franciscano, Rua Silva Jardim, 1323, Conjunto II, CEP 97010-491, Santa Maria (RS), Brasil. vagnercbressan@gmail.com

Recebido para publicação em 28/03/2011 e aceito em 19/07/2013 
mapping vegetation, soil and topography. Crossed the historical information of use and occupation of transects conducted in 2009, the digital terrain model, maps of land cover for 1987 and 2009 and soil, thus deriving a transitory component landscape, between the plateau border Southern and Central Depression of Rio Grande do Sul state, with a distortion of the natural vegetation types and conflicts of land use, as well as the influence of topography and soil genesis on the vegetation development. There was expansion in 22 years of Eucalyptus and Pinus crops and the natural forest on the anthropic field, especially in areas with Argissolos Bruno-Acinzentados and Argissolos Vermelhos.

Keywords: landscape components; geoprocessing; temporal variation.

\section{INTRODUÇÃO}

Os cultivos florestais são considerados os principais agentes de transformação da paisagem, e são alvos de inúmeras controvérsias quanto aos seus efeitos no ambiente. A busca por técnicas de estudo da paisagem é, portanto, imprescindível para o monitoramento e planejamento da ocupação das terras.

A paisagem abrange os componentes naturais, os fatores de intervenção humana e as qualidades estéticas. Como componentes naturais importantes, têm-se a geomorfologia e a vegetação e, como fatores de intervenção, têm-se o manejo da vegetação. Os fatores estéticos estão relacionados à reação mental do que os olhos veem (LUCAS, 1991). Deve-se incluir, dentre os componentes (estrutura) da paisagem o solo, os componentes geológicos e o clima (DEMATTÊ, 1997); destes, os dois primeiros são poucas vezes abordados nos trabalhos de ecologia da paisagem, e atualmente estão chamando mais atenção, devido aos possíveis efeitos dos monocultivos florestais sobre a qualidade do solo e a dinâmica da água na paisagem.

Deste modo, a ecologia da paisagem é a linha da ecologia cujos resultados provêm da inter-relação entre o homem e a paisagem (PORTO; MENEGAT, 2004), os quais são obtidos principalmente com o emprego de técnicas de geoprocessamento. Com o uso de ferramentas de sensoriamento remoto e do sistema de informações geográficas (SIG), o geoprocessamento permite a visualização de áreas ou fenômenos específicos e a percepção de conexões, padrões e estruturas referentes aos objetos mapeados (KRAAK; ORMELING, 1996; YOUNG et al., 1993), o que facilita a análise de componentes geomorfológicos, da vegetação e do solo e de suas relações através da sobreposição de Planos de Informação (PIs).

Os atributos do terreno são os indicadores mais utilizados no mapeamento digital de solos
(MCBRATNEY et al., 2003), sendo o relevo um dos mais importantes fatores para sua formação (JENNY, 1941). O grau de desenvolvimento dos solos, por sua vez, tem implicação na vegetação, haja vista as alterações ao longo da paisagem da disponibilidade de água, quantidade de nutrientes e textura do solo (CLARK, 2002).

As áreas com elevada variabilidade geomorfológica, vegetal e edáfica apresentam desafios para a caracterização paisagística, principalmente na transição entre grandes biomas, como observado no município gaúcho de Santa Maria - RS. Trata-se de um limite transitório do bioma de Mata Atlântica com o Pampa, onde está localizada a Estação Experimental de Silvicultura de Santa Maria (Fepagro Florestas), importante sítio de pesquisas dos recursos florestais.

A inexistência de informações atualizadas, no que se refere aos componentes da paisagem da Fepagro Florestas, estimulou o desenvolvimento do presente estudo. Este tipo de trabalho é fundamental para dar suporte às pesquisas de solos, fauna e flora, restauração da vegetação nativa, planejamento da silvicultura e gestão integrada das terras.

Assim, este trabalho teve por objetivo caracterizar os componentes da paisagem, tais como o relevo, a cobertura vegetal e suas relações com os solos, além de avaliar a variação temporal da relação solo/paisagem entre os anos de 1987 e 2009.

\section{MATERIAL E MÉTODOS}

\section{Meio Biofísico}

O estudo foi desenvolvido na Estação Estadual de Pesquisas Florestais (Fepagro Florestas) no município de Santa Maria, Estado do Rio Grande do Sul. Com área de aproximadamente 538 ha, a estação está inserida nas coordenadas UTM 216.000 e $220.000 \mathrm{E}, 6.713 .000$ e $6.717 .000 \mathrm{~S}$ (fuso22S); o clima da região enquadra-se na classificação de 


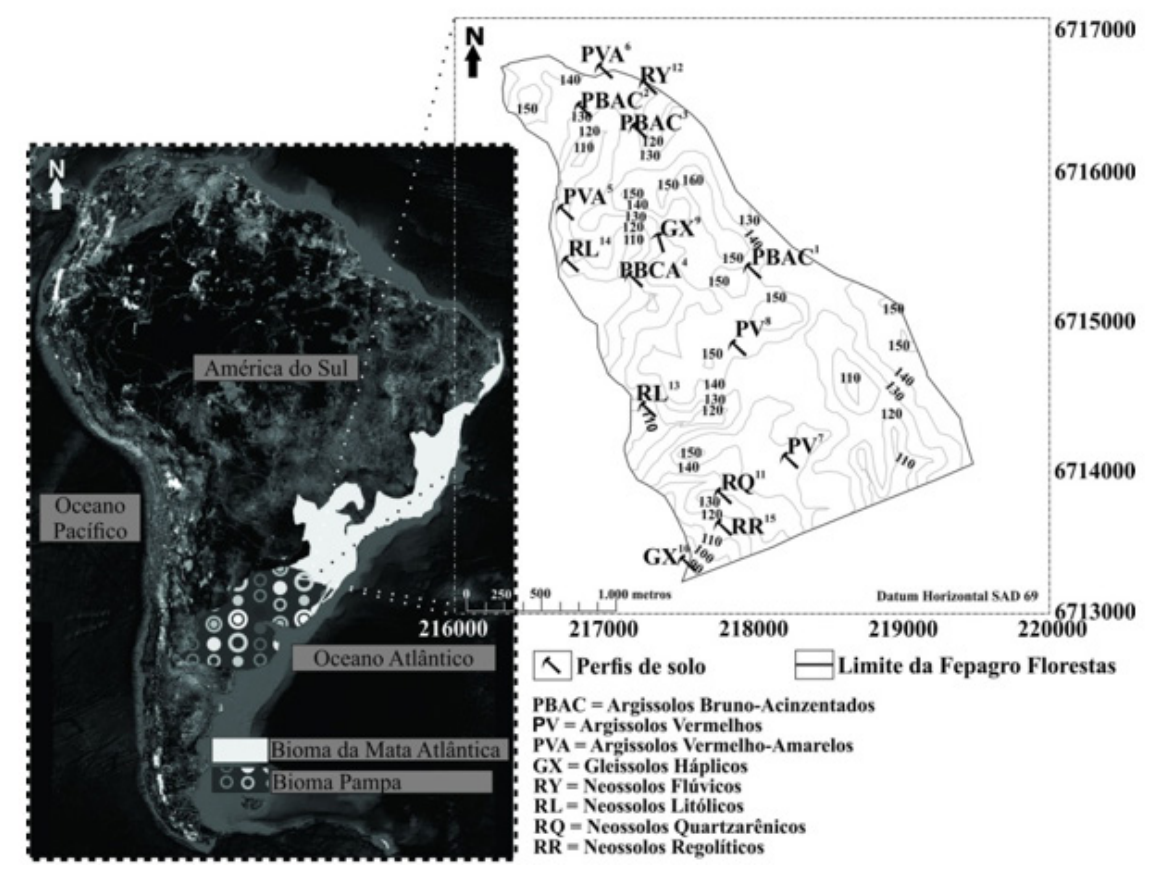

FIGURA 1: Localização da Fepagro Florestas e dos perfis de solo descritos por Abrão et al. (1988) sobre o mapa planialtimétrico da Fepagro Florestas.

FIGURE 1: Location of Fepagro Forests and soil profiles studied by Abrão et al. (1988) on the planialtimetric map of Fepagro Forests.

Köppen como Cfa (clima subtropical úmido, com temperatura média anual de $19^{\circ} \mathrm{C}$ e pluviosidade média anual de $1733 \mathrm{~mm}$ ) (Figura 1).

O local apresenta características geológicas complexas, predominando a Formação Rosário do Sul, com depósitos aluvionares, areias, cascalheiras e sedimentos síltico-argilosos de planícies de inundação, terraços e depósitos de calha da rede fluvial atual e subatual, apresentando inclusões da Formação Serra Geral com rochas vulcânicas tipo: basalto e riolito, e da Formação Botucatu com arenitos eólicos (IBGE, 2003).

$\mathrm{Na}$ região predominam fitofisionomias classificadas como de Tensão Ecológica com Atividades Agrárias (IBGE, 2004), estabelecidas sobre Argissolos Bruno-Acinzentados, Argissolos Vermelhos, Argissolos Vermelho-Amarelos, Gleissolos Háplicos, Neossolos Flúvicos, Neossolos Litólicos, Neossolos Quartzarênicos e Neossolos Regolíticos (ABRÃO et al., 1988), em relevo suavemente ondulado a ondulado com elevações de 90 a $174 \mathrm{~m}$.

\section{Métodos de campo, laboratório e escritório}

Sobre o Mapa Planimétrico da Fepagro Florestas do ano de 1987, na escala 1:5.000, foi gerada a base cartográfica (AGUIRRE, 1987).

Para a elaboração do Modelo Numérico do Terreno (MNT) foram utilizados dados da Shuttle Radar Topography Mission (SRTM), com resolução espacial de $90 \mathrm{~m}$. Foram extraídas curvas de contorno dos dados SRTM, com intervalo de 15 metros visando manter a fidelidade da imagem. Dos contornos, gerou-se uma grade e a nova imagem foi submetida ao refinamento de grade regular (interpolador bicúbico), resultando na resolução espacial de 10 metros (VALERIANO, 2004). Posteriormente, foi construído o modelo de superfície, baseado na representação Triangular Irregular Network (TIN).

Durante os procedimentos de campo, o georreferenciamento dos pontos de interesse foi realizado com o receptor dos Sistemas Globais de Navegação por Satélite (GNSS), código CA (com a média de observações no ponto).

A caracterização florística, para o ano de 2009, foi realizada através de transecções com especialista botânico, identificando a ocorrência de espécies conforme APG III (2009). Os estágios sucessionais foram descritos em função do CONAMA (2012). Foram avaliados também, os aspectos da paisagem relacionados à vegetação.

Para o estudo do componente solo foram 
TABELA 1: Perfis de solo descritos por Abrão et al. (1988), e suas respectivas classes texturais.

TABLE 1: Soil profiles described by Abrão et al. (1988), and their texture classes.

\begin{tabular}{|c|c|c|c|c|c|c|c|}
\hline \multirow{2}{*}{ Classe de solo } & \multirow{2}{*}{ Horizonte } & \multirow{2}{*}{ Profundidade (m) } & \multicolumn{4}{|c|}{ Composição granulométrica g. $\mathrm{kg}^{-1}$} & \multirow{2}{*}{ Classe Textural } \\
\hline & & & Areia grossa & Areia fina & Silte & Argila & \\
\hline \multirow{6}{*}{$\mathrm{PBAC}_{1}$} & $A_{p}$ & $0,00-0,27$ & 250 & 460 & 140 & 150 & Franco-arenoso \\
\hline & $\mathrm{A}_{12}$ & $0,27-0,36$ & 220 & 410 & 170 & 290 & Franco-argiloarenoso \\
\hline & $\mathrm{B}_{1}$ & $0,36-0,61$ & 180 & 320 & 210 & 290 & Franco-argiloarenoso \\
\hline & $\mathrm{B}_{2} \mathrm{t}$ & $0,61-0,69$ & 100 & 190 & 250 & 460 & Argiloso \\
\hline & $\mathrm{B}_{3} \mathrm{t}$ & $0,69-1,12$ & 80 & 180 & 230 & 510 & Argiloso \\
\hline & IIC & $1,12-1,30$ & 50 & 220 & 560 & 170 & Franco-siltoso \\
\hline \multirow{4}{*}{$\mathrm{PBAC}_{2}$} & $A_{p}$ & $0,00-0,17$ & 270 & 350 & 210 & 170 & Franco-arenoso \\
\hline & $\mathrm{A}_{3}$ & $0,17-0,55$ & 220 & 270 & 250 & 260 & Argiloso \\
\hline & $\mathrm{B}_{2} \mathrm{t}$ & $0,55-0,85$ & 140 & 190 & 150 & 520 & Argiloso \\
\hline & $\mathrm{IIB}_{3} \mathrm{t}$ & $0,85-1,12$ & 70 & 220 & 240 & 470 & Argiloso \\
\hline \multirow{3}{*}{$\mathrm{PBAC}_{3}$} & $\mathrm{~A}_{1}$ & $0,00-0,35$ & 200 & 400 & 200 & 200 & Franco-argiloarenoso \\
\hline & $\mathrm{IIB}_{2} \mathrm{t}$ & $0,35-0,62$ & 30 & 220 & 290 & 460 & Argiloso \\
\hline & $\mathrm{IIC}_{1}$ & $0,62-0,86$ & 30 & 160 & 410 & 400 & Franco-argilossiltoso \\
\hline \multirow{5}{*}{$\mathrm{PBAC}_{4}$} & $\mathrm{~A}_{1}$ & $0,00-0,35$ & 260 & 220 & 190 & 330 & Franco-argiloarenosa \\
\hline & $\mathrm{IIB}_{21} \mathrm{t}$ & $0,35-0,55$ & 80 & 90 & 190 & 640 & Muito argiloso \\
\hline & $\mathrm{IIB}_{22} \mathrm{t}$ & $0,55-0,74$ & 40 & 90 & 220 & 650 & Muito argiloso \\
\hline & $\mathrm{IIB}_{23} \mathrm{t}$ & $0,74-1,00$ & 30 & 110 & 270 & 590 & Argiloso \\
\hline & IIIC $_{1}$ & $1,00-1,25$ & 380 & 240 & 140 & 240 & Franco-argiloarenoso \\
\hline \multirow{6}{*}{$\mathrm{PVA}_{5}$} & $A_{p}$ & $0,00-0,20$ & 480 & 320 & 120 & 80 & Franco-arenoso \\
\hline & $\mathrm{A}_{12}$ & $0,20-0,43$ & 460 & 310 & 140 & 90 & Franco-arenoso \\
\hline & $\mathrm{A}_{13}$ & $0,43-0,69$ & 410 & 330 & 140 & 120 & Franco-arenoso \\
\hline & $\mathrm{A}_{2}$ & $0,69-0,96$ & 410 & 400 & 120 & 70 & Franco-arenoso \\
\hline & BA & $0,96-1,12$ & 310 & 340 & 160 & 190 & Franco-arenoso \\
\hline & $\mathrm{B}_{2}$ & $1,12-1,35$ & 290 & 250 & 180 & 280 & Franco-argiloarenoso \\
\hline \multirow{4}{*}{$\mathrm{PVA}_{6}$} & Ap & $0,00-0,20$ & 380 & 340 & 150 & 130 & Franco-arenoso \\
\hline & $\mathrm{A}_{12}$ & $0,20-0,47$ & 310 & 410 & 150 & 130 & Franco-arenoso \\
\hline & $\mathrm{A}_{2}$ & $0,47-0,71$ & 300 & 470 & 160 & 70 & Franco-arenoso \\
\hline & $\mathrm{B}_{2}$ & $0,71-1,00$ & 240 & 280 & 180 & 300 & Franco-argiloarenoso \\
\hline \multirow{5}{*}{$\mathrm{PV}_{7}$} & $A_{p}$ & $0,00-0,30$ & 400 & 260 & 120 & 220 & Franco-argiloarenoso \\
\hline & $\mathrm{A}_{3}$ & $0,30-0,56$ & 200 & 410 & 110 & 280 & Franco-argiloarenoso \\
\hline & $\mathrm{B}_{21}$ & $0,56-0,85$ & 70 & 430 & 150 & 350 & Franco-argiloarenoso \\
\hline & $\mathrm{B}_{22}$ & $0,85-1,26$ & 120 & 310 & 130 & 440 & Argiloso \\
\hline & $\mathrm{B}_{3}$ & $1,26-1,50$ & 140 & 240 & 130 & 490 & Argiloso \\
\hline \multirow{4}{*}{$\mathrm{PV}_{8}$} & $\mathrm{~A}_{1}$ & $0,00-0,42$ & 440 & 280 & 100 & 180 & Franco-arenoso \\
\hline & $\mathrm{B}_{1}$ & $0,42-0,65$ & 320 & 410 & 90 & 180 & Franco-arenoso \\
\hline & $\mathrm{B}_{21}$ & $0,65-1,14$ & 240 & 380 & 100 & 280 & Franco-argiloarenoso \\
\hline & $\mathrm{B}_{22}$ & $1,14-1,40$ & 160 & 380 & 130 & 330 & Franco-argiloarenoso \\
\hline \multirow{3}{*}{$\mathrm{GX}_{9}$} & $\mathrm{~A}_{11}$ & $0,0-0,27$ & 380 & 260 & 180 & 180 & Franco-arenoso \\
\hline & $\mathrm{A}_{12}$ & $0,27-0,45$ & 380 & 230 & 200 & 190 & Franco-arenoso \\
\hline & $\mathrm{C}_{\mathrm{g}}$ & $0,45-0,65$ & 380 & 230 & 170 & 220 & Franco-argiloarenoso \\
\hline
\end{tabular}

Continua ... 
TABELA 1: Continuação ...

TABLEA 1: Continued ...

\begin{tabular}{|c|c|c|c|c|c|c|c|}
\hline \multirow{2}{*}{ Classe de solo } & \multirow{2}{*}{ Horizonte } & \multirow{2}{*}{ Profundidade (m) } & \multicolumn{4}{|c|}{ Composição granulométrica g. $\mathrm{kg}^{-1}$} & \multirow{2}{*}{ Classe Textural } \\
\hline & & & Areia grossa & Areia fina & Silte & Argila & \\
\hline \multirow{4}{*}{$\mathrm{GX}_{10}$} & $A_{p}$ & $0,0-0,15$ & 20 & 50 & 390 & 540 & Argiloso \\
\hline & $\mathrm{A}_{3}$ & $0,15-0,30$ & 30 & 110 & 370 & 490 & Argiloso \\
\hline & $\mathrm{IIC}_{\mathrm{lg}}$ & $0,30-0,80$ & 30 & 210 & 530 & 230 & Franco-siltoso \\
\hline & $\mathrm{IIC}_{2 \mathrm{~g}}$ & $0,80-1,0$ & 30 & 250 & 460 & 260 & Franco \\
\hline \multirow{5}{*}{$\mathrm{RQ}_{11}$} & $A_{p}$ & $0,0-0,30$ & 540 & 340 & 40 & 80 & Franco-arenoso \\
\hline & $\mathrm{A}_{12}$ & $0,30-0,60$ & 500 & 320 & 90 & 90 & Franco-arenoso \\
\hline & $\mathrm{A}_{13}$ & $0,60-0,93$ & 580 & 310 & 30 & 80 & Arenoso \\
\hline & $\mathrm{C}_{1}$ & $0,93-1,25$ & 560 & 310 & 40 & 90 & Franco-arenoso \\
\hline & $\mathrm{C}_{2}$ & $1,25-1,45$ & 700 & 180 & 30 & 90 & Franco-arenoso \\
\hline \multirow{6}{*}{$\mathrm{RY}_{12}$} & $\mathrm{~A}_{11}$ & $0,0-0,17$ & 120 & 230 & 260 & 390 & Franco-argiloso \\
\hline & $\mathrm{A}_{12}$ & $0,17-0,30$ & 60 & 150 & 350 & 440 & Franco-argiloso \\
\hline & $\mathrm{IIC}_{1}$ & $0,30-0,38$ & 230 & 280 & 250 & 240 & Franco-argiloarenoso \\
\hline & $\mathrm{IIIC}_{2}$ & $0,38-0,47$ & 50 & 240 & 270 & 440 & Argiloso \\
\hline & $\mathrm{IVC}_{3}$ & $0,47-0,82$ & 290 & 330 & 160 & 220 & Franco-argiloarenoso \\
\hline & $\mathrm{VC}_{3}$ & $0,82-1,15$ & 260 & 270 & 170 & 300 & Franco-argiloarenoso \\
\hline $\mathrm{RL}_{13}$ & $\mathrm{~A}_{1}$ & $0,0-0,50$ & 130 & 580 & 120 & 170 & Franco-arenoso \\
\hline \multirow{2}{*}{$\mathrm{RL}_{14}$} & $A_{p}$ & $0,0-0,16$ & 430 & 300 & 100 & 170 & Franco-arenoso \\
\hline & $\mathrm{A}_{12}$ & $0,16-0,30$ & 460 & 180 & 130 & 230 & Franco-arenoso \\
\hline \multirow{4}{*}{$\mathrm{RR}_{15}$} & $\mathrm{~A}_{11}$ & $0,0-0,22$ & 360 & 430 & 80 & 130 & Franco-arenoso \\
\hline & $\mathrm{A}_{12}$ & $0,22-0,49$ & 340 & 420 & 80 & 160 & Franco-arenoso \\
\hline & $\mathrm{AC}$ & $0,49-0,62$ & 240 & 500 & 100 & 160 & Franco-arenoso \\
\hline & $\mathrm{C}$ & $0,62-1,10$ & 70 & 700 & 100 & 130 & Franco-arenoso \\
\hline
\end{tabular}

Em que: $\mathrm{PBAC}=$ Argissolos Bruno-Acinzentados; $\mathrm{PV}=$ Argissolos Vermelhos; $\mathrm{PVA}=$ Argissolos Vermelho-Amarelos; GX = Gleissolos Háplicos; RY = Neossolos Flúvicos; RL = Neossolos Litólicos; RQ = Neossolos Quartzarênicos e $\mathrm{RR}=$ Neossolos Regolíticos.

utilizados 15 perfis descritos por Abrão et al (1988) (Tabela 1), os quais foram relacionados ao relevo (Figura 1).

Foi elaborado um mapa de solos com a conversão da carta de solos de Abrão et al. (1988) para o meio digital. Posteriormente, a imagem (mapa de solos), como os demais planos de informação (PIs) foram georreferenciados com a projeção UTM no sistema geodésico SAD 69 (fuso 22 - Sul), enquanto as classes de solos foram vetorizadas e atualizadas para o segundo nível categórico do Sistema Brasileiro de Classificação de Solos (EMBRAPA, 2006), resultando em um PI com 3 metros de resolução espacial. Em seguida, procedeu-se a verificação de campo por meio de transecções com tradagens para a avaliação de características morfológicas do solo, conforme estabelecido pelo IBGE (IBGE, 2007).
A elaboração dos mapas de cobertura vegetal de 1987 e 2009 (PIs com resolução espacial de 3 metros) foi realizada por meio de coletas de informações sobre o histórico recente de uso do solo, da base cartográfica (Mapa Planimétrico de 1987 da Fepagro Florestas), da verificação de campo e da vetorização da imagem do sensor Quick Bird, fornecida pela empresa Digital Globe e disponível no software Google Earth (GOOGLE, 2009) de 28 de julho de 2009.

As inter-relações entre o relevo, solos e cobertura vegetal, nas diferentes datas foram realizadas com base nos cruzamentos entre os PIs: MNT (1), Mapa de Solos (2), Mapa de Cobertura Vegetal de 1987 (3) e Mapa de Cobertura Vegetal de 2009 (4) (Figura 2). 


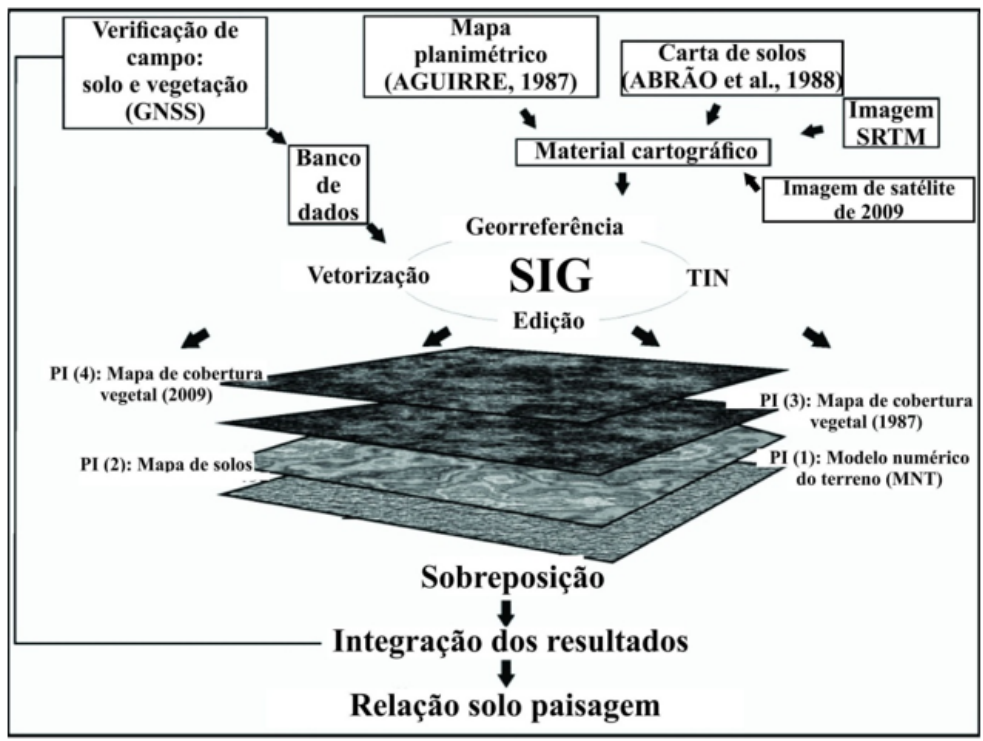

FIGURA 2: Esquema metodológico e integração dos resultados.

FIGURE 2: Methodological scheme and integration of research results.

\section{RESULTADOS E DISCUSSÃO}

\section{Relação solo/paisagem}

A sobreposição dos PIs 1 e 2 mostrou que os Argissolos Bruno-Acinzentados (PBAC), com textura franco-arenosa a franco-argiloarenosa no Horizonte A (espessura média de $0,28 \mathrm{~m}$ ), ocupam 137 ha da área de estudo, possuindo perfis com 0,86 a $1,30 \mathrm{~m}$ de espessura. Esses solos apresentam incremento de argila em profundidade, derivandose de siltitos e argilitos da Formação Rosário do Sul (IBGE, 2003) e ocorrem em cotas de elevação que variam de 105,6 a $160 \mathrm{~m}$ de altitude, em relevo suave ondulado a forte ondulado (Tabela 1, Figuras $3 \mathrm{~A}$ e 3B). Comparando os perfis de $\mathrm{PBAC}_{1}$ a 140 $\mathrm{m}$ de elevação, $\mathrm{PBAC}_{2}$ a $130 \mathrm{~m}, \mathrm{PBAC}_{3}$ a $120 \mathrm{~m}$, e $\mathrm{PBAC}_{4}$ a $120 \mathrm{~m}$, é possível observar a maior incorporação da argila nas camadas superficiais e subsuperficiais dos perfis desenvolvidos em áreas de deposição (Tabela 1; Figuras 1, 3A e 3B). Esse processo foi observado por Quine \& Zhang (2002), durante o estudo da variação espacial da erosão e das propriedades dos solos agrícolas no Reino Unido. Observa-se, também a ocorrência de glebas com terreno ravinado associadas ao PBAC. Nessas glebas, há a depressão abrupta da altimetria, condição que contribuí para a conformação de processos erosivos na forma de grandes voçorocas, com até 4,5 m de profundidade (Figuras 3A e 3B).

Os Argissolos Vermelho-Amarelos (PVA) desenvolvem-se sobre arenitos da Formação Botucatu (IBGE, 2003) em 42 ha da área, com textura franco-arenosa no Horizonte A, com perfis de 1,00 a $1,35 \mathrm{~m}$ de profundidade, os quais apresentam um pequeno incremento de argila em profundidade. São encontrados em elevações que variam de 105,6 a 152,2 $\mathrm{m}$, em relevo suave ondulado a ondulado (Tabela 1, Figuras 3A e 3B). Os Argissolos Vermelhos (PV) são encontrados em 206 ha, desenvolvendo-se em relevo suave ondulado a ondulado, em elevações que variam de 113,3 a 152,2 m, são formados a partir de arenitos da Formação Botucatu, com influência de rochas efusivas basálticas da Formação Serra Geral (IBGE, 2003). Têm textura franco-arenosa a franco-argiloarenosa no Horizonte A, apresentando incremento de argila em profundidade em perfis com 1,40 a mais de 1,50 $\mathrm{m}$ (Tabela 1, Figuras 3A e 3B).

Na porção norte da paisagem, sobre materiais aluviais e coluviais (IBGE, 2003) desenvolvemse os Neossolos Flúvicos (RY) em relevo plano a ondulado, principalmente em áreas úmidas, nas cotas de elevação que variam de 105,6 a 144,4 m. Estes solos ocupam 12 ha da área e têm textura franco-argilosa no Horizonte A com perfil de solo de $1,15 \mathrm{~m}$ (Tabela 1, Figuras 3A e 3B). No sul foram mensurados 17 ha de Neossolos Quartzarênicos (RQ), em elevações de 144,4 a 105,6 m. Os perfis de RQ apresentam Horizonte A com textura areiafranca e profundidade de 1,45 $\mathrm{m}$ (Tabela 1, Figuras 3A e 3B). 


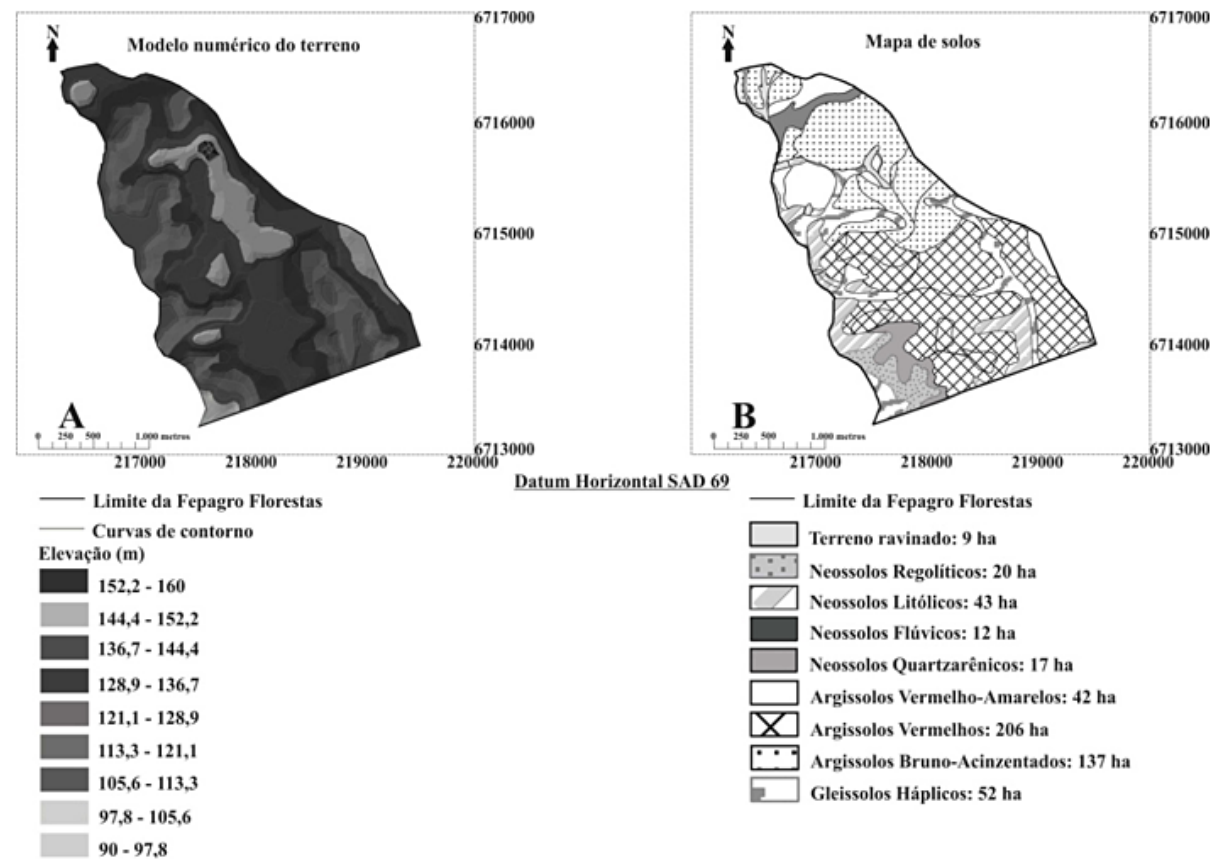

FIGURA 3: A. Modelo numérico do terreno (MNT), B. mapa de Solos da Fepagro Florestas. FIGURE 3: A. Digital terrain model (DTM), B. soil map of Fepagro Forests.

As glebas com maior declividade sobre a Formação Rosário do Sul (IBGE, 2003) apresentam Neossolos Litólicos (RL) com 43 ha e Neossolos Regolíticos (RR) com 20 ha, nas cotas de elevação que variam de 144,4 a $97,8 \mathrm{~m}$. Os RL desenvolvemse sobre arenito e siltito, com $0,40 \mathrm{~m}$ de espessura média e textura franco-arenosa, enquanto que os $\mathrm{RR}$, por sua vez, têm textura franco-arenosa, com espessura próxima a $0,50 \mathrm{~m}$ (Tabela 1, Figuras 3A e 3B). A espessura desses solos está associada à instabilidade geomórfica das escarpas, sendo que nessas áreas há o intenso processo de desagregação do solo e o transporte de sedimentos para as cotas mais deprimidas da paisagem. Vidal-Torrado \& Lepsch (1999) observaram que há relação cronológica entre os solos e as superfícies geomórficas, sendo que superfícies menos estáveis possuem, normalmente, solos menos desenvolvidos e mais variados.

De 144,4 a $90 \mathrm{~m}$ de elevação, são observadas áreas úmidas sobre sedimentos aluviais, onde se desenvolvem Gleissolos Háplicos (GX) distribuídos em 52 ha, com perfis de solo com espessura de 0,65 a $1,0 \mathrm{~m}$. Comparando os perfis $\mathrm{GX}_{9}$ a $130 \mathrm{~m}$ de elevação e $\mathrm{GX}_{10}$ a $90 \mathrm{~m}$ é possível constatar o incremento da argila no Horizonte A passando de franco-arenosa a argila na área mais baixa, como também no restante do perfil. Os efeitos da posição na paisagem também são observados entre os contrastes da textura no Horizonte A de $\mathrm{PVA}_{5}$ PVA $_{6}$ e $\mathrm{PV}_{8}$ com GX $\mathrm{G}_{10}$ e RY ${ }_{12}$, além do desenvolvimento em profundidade para a maioria dos perfis de solos descritos por Abrão (1988) (Tabela 1, Figuras 3A e 3B). Para Anjos et al. (1998), dentre os fatores de formação dos solos destaca-se o relevo, o qual coordena e direciona os fluxos de água nos perfis do solo, aliado a outro importante fator para a gênese que é o material de origem, o qual dita as condições químicas e físicas do solo.

A área de estudo apresentou classes de solo características do Rebordo do Planalto SulRiograndense e da Depressão Central do Rio Grande do Sul (STRECK et al., 2008), fato que confere caráter edáfico transitório à Estação Experimental.

\section{Variação espacial da vegetação}

Ao longo da paisagem, as formações campestres apresentam composição botânica envolvendo 24 espécies de 21 gêneros pertencentes a 12 famílias botânicas. Destacam-se as famílias Poaceae, com sete espécies de sete gêneros botânicos, e Asteraceae, com cinco espécies de quatro gêneros. Espécies como Eryngium $s p$ (Apiaceae) e Cyperus sp (Cyperaceae) foram registradas principalmente em áreas úmidas sob GX 
(Tabela 2, Figura 4B). Além da prática de pecuária extensiva, pode ser evidenciada a descaracterização botânica do campo antrópico pela presença de Eragrostis plana (Tabela 2), espécie naturalizada à flora gaúcha (SCHNEIDER, 2007).

Os fragmentos florestais apresentam 59 espécies de 50 gêneros botânicos, pertencentes a 31 famílias (Figura 4B). Destas, a família mais representativa é a Myrtaceae, com sete espécies de cinco gêneros, seguida das famílias Rutaceae, com quatro espécies pertencentes a quatro gêneros botânicos, e Mimosaceae, com quatro espécies de três gêneros (Tabela 3). Os grupos ecológicos são compostos principalmente por Pioneiras e Secundárias Iniciais, o que reforça a classificação das florestas nativas nos estágios inicial e médio de regeneração, tendo as espécies, em geral, distribuição na Floresta Estacional Decidual e na
Estepe Gramíneo-lenhosa, ratificando o caráter transitório da área (SEMA, 2007; LEITE, 2002).

A descaracterização dos fragmentos florestais foi nítida, dada a presença de espécies exóticas, como Citrus nobilis (Rutaceae), Eucalyptus sp. (Myrtaceae), Hovenia dulcis (Rhamnaceae), Melia azedarach (Meliaceae), Acacia mearnsii (Mimosaceae) e Pinus sp. (Pinaceae), mescladas à vegetação nativa (Tabela 3 ) principalmente em áreas já exploradas, sob sucessão natural.

A maior incidência de indivíduos de Calliandra selloi (Leguminosae) foi registrada em matas ripárias associadas à RL e RR, Erythrina cristagalli (Fabaceae) em áreas úmidas associadas a GX e PBAC, Myrcianthes gigantea (Myrtaceae) em mata ripária associada a RR, Myrsine lorentziana (Myrsinaceae) e Phyllanthus sellowianus (Euphorbiaceae) em matas ripárias associadas a

TABELA 2: Relação de espécies campestres registradas na Fepagro Florestas e seu ambiente preferencial. TABLE 2: Relation of grassland species recorded in Fepagro Forests and their favorite environment.

\begin{tabular}{|c|c|c|}
\hline Espécies & Família & Ambiente preferencial \\
\hline Eryngium horridum & Apiaceae & \\
\hline Eryngium sp. & Apiaceae & área úmida associada a GX \\
\hline Achyrocline satureioides & Asteraceae & \\
\hline Baccharis sp. & Asteraceae & \\
\hline Baccharis trimera & Asteraceae & \\
\hline Bidens pilosa & Asteraceae & \\
\hline Soliva pterosperma & Asteraceae & \\
\hline Cyperus rotundus & Cyperaceae & \\
\hline Cyperus sp. & Cyperaceae & área úmida associada a $\mathrm{GX}$ \\
\hline Desmodium incanum & Fabaceae & \\
\hline Rosmarinus officinalis & Lamiaceae & \\
\hline Trifolium sp. & Leguminosae & \\
\hline Sida rhombifolia & Malvaceae & \\
\hline Phyllantus corcovadensis & Phyllanthaceae & \\
\hline Aristida pallens & Poaceae & \\
\hline Cynodon sp. & Poaceae & \\
\hline Eragrostis plana & Poaceae & \\
\hline Erianthus sp & Poaceae & \\
\hline Paspalum notatum & Poaceae & \\
\hline Rhynchelytrum repens & Poaceae & \\
\hline Schizachyryum condensatum & Poaceae & \\
\hline Rumex crispus & Polygonaceae & \\
\hline Smilax sp & Smilacaceae & \\
\hline Urtica dioica & Urticaceae & \\
\hline
\end{tabular}

Em que: GX = Gleissolos Háplicos. 
TABELA 3: Relação de espécies registradas nos fragmentos florestais da Fepagro Florestas e seu ambiente preferencial.

TABLE 3: Value of recorded species in forest fragment of Fepagro Forests and their favorite environment.

\begin{tabular}{|c|c|c|}
\hline Espécies & Família & Ambiente preferencial \\
\hline Lithraea molleoides & Anacardiaceae & \\
\hline Schinus molle & Anacardiaceae & \\
\hline Schinus terebinthifolius & Anacardiaceae & \\
\hline Rollinia sylvatica & Annonaceae & \\
\hline Araucaria angustifolia & Araucariaceae & \\
\hline Syagrus romanzoffiana & Arecaceae & \\
\hline Baccharis tridentata & Asteraceae & \\
\hline Tabebuia alba & Bignoniaceae & \\
\hline Tabebuia chrysotricha & Bignoniaceae & \\
\hline Tabebuia heptaphylla & Bignoniaceae & \\
\hline Cordia trichotoma & Boraginaceae & \\
\hline Patagonula americana & Boraginaceae & \\
\hline Pelthophorum dubium & Caesalpiniaceae & \\
\hline Erythroxylum deciduum & Erythroxylaceae & \\
\hline Phyllanthus sellowianus & Euphorbiaceae & matas ripárias associadas a PBAC, $\mathrm{RY}, \mathrm{RL}$ e $\mathrm{RR}, \mathrm{GX}$ e no TR \\
\hline Sebastiania brasiliensis & Euphorbiaceae & matas ripárias associadas a PBAC, $\mathrm{RY}, \mathrm{RL}$ e $\mathrm{RR}, \mathrm{GX}$ e no TR \\
\hline Sebastiania commersoniana & Euphorbiaceae & \\
\hline Dalbergia frutescens & Fabaceae & \\
\hline Erythrina cristagalli & Fabaceae & áreas úmidas associadas a $\mathrm{GX}, \mathrm{PBAC}$ \\
\hline Machaerium paraguariense & Fabaceae & \\
\hline Casearia sylvestris & Flacourtiaceae & \\
\hline Xylosma venosum & Flacourtiaceae & \\
\hline Nectandra lanceolata & Lauraceae & \\
\hline Nectandra megapotamica & Lauraceae & \\
\hline Ocotea puberula & Lauraceae & \\
\hline Calliandra selloi & Leguminosae & matas ripárias associadas a $\mathrm{RL}$ e $\mathrm{RR}$ \\
\hline Cabralea canjerana & Meliaceae & \\
\hline Cedrela fissilis & Meliaceae & \\
\hline Melia azedarach. & Meliaceae & \\
\hline Acacia mearnsii & Mimosaceae & \\
\hline Acacia bonariensis & Mimosaceae & \\
\hline Enterolobium contortisiliquum & Mimosaceae & \\
\hline Parapiptadenia rigida & Mimosaceae & \\
\hline Ficus luschnathiana & Moraceae & \\
\hline Myrsine lorentziana & Myrsinaceae & matas ripárias associadas a PBAC, $\mathrm{RY}, \mathrm{RL}$ e $\mathrm{RR}, \mathrm{GX}$ e no TR \\
\hline Myrsine umbellata & Myrsinaceae & \\
\hline Blepharocalyx salicifolius & Myrtaceae & \\
\hline Campomanesia xanthocarpa & Myrtaceae & \\
\hline Eucalyptus sp. & Myrtaceae & \\
\hline Eugenia involucrata & Myrtaceae & \\
\hline Eugenia uniflora & Myrtaceae & \\
\hline
\end{tabular}


TABELA 3: Continuação ...

TABLE 3: Continued ...

\begin{tabular}{|c|c|c|}
\hline Espécies & Família & Ambiente preferencial \\
\hline Eugenia uruguayensis & Myrtaceae & \\
\hline Myrcianthes gigantea & Myrtaceae & mata ripária associada a $R R$ \\
\hline Butia capitata & Palmae & \\
\hline Pinus sp. & Pinaceae & \\
\hline Hovenia dulcis & Rhamnaceae & \\
\hline Prunus myrtifolia & Rosaceae & \\
\hline Citrus nobilis & Rutaceae & \\
\hline Helietta apiculata & Rutaceae & \\
\hline Zanthoxylum fagara & Rutaceae & \\
\hline Zanthoxylum rhoifolium & Rutaceae & \\
\hline Allophylus edulis & Sapindaceae & \\
\hline Cupania vernalis & Sapindaceae & \\
\hline Matayba elaeagnoides & Sapindaceae & \\
\hline Solanum mauritianum. & Solanaceae & \\
\hline Luehea divaricata. & Tiliaceae & \\
\hline Celtis iguanaea & Ulmaceae & \\
\hline Urera baccifera & Urticaceae & \\
\hline Vitex megapotamica & Verbenaceae & \\
\hline
\end{tabular}

Em que: $\mathrm{PBAC}=$ Argissolos Bruno-Acinzentados; $\mathrm{PV}=$ Argissolos Vermelhos; $\mathrm{PVA}=$ Argissolos Vermelho-Amarelos; GX = Gleissolos Háplicos; RY = Neossolos Flúvicos; RL = Neossolos Litólicos; RQ = Neossolos Quartzarênicos e $\mathrm{RR}=$ Neossolos Regolíticos.

PBAC, RY, RL e RR, GX e TR (Tabela 3, Figuras 3B e 4B), o que evidencia o contato vegetal do tipo ecótono (edáfico) (IBGE, 2004).

A sobreposição dos PIs 3 e 4 revela a ocorrência de seis classes fitofisionômicas no ano de 1987, sendo o campo antrópico a mais representativa com 320 ha, seguido de cultivos do gênero Eucalyptus com 92 ha, floresta nativa com 34 ha, cultivos do gênero Pinus com 34 ha, cultivos florestais diversos com 33 ha e cultivos agrícolas com apenas 5 ha. Para o ano de 2009, houve a redução para cinco classes, tendo destaque o decréscimo na ocupação do campo antrópico para 143 ha. Os 177 ha anteriormente ocupados por campo antrópico cederam espaço para floresta nativa com 138 ha, cultivos de Eucalyptus com 121 ha e cultivos de Pinus com 67 ha. Constatou-se um balanço temporal positivo para a floresta nativa, bem como a expansão dos cultivos de Eucalyptus e Pinus (Figuras 4A e 4B). Essas mudanças estão atreladas principalmente à alteração na forma de exploração da Fepagro Florestas e às condições ambientais ocasionadas pelos demais elementos da paisagem.
A sobreposição dos PIs 1, 2, 3 e 4 mostra que o campo antrópico tem distribuição temporal nas diferentes classes de solo e no terreno ravinado (TR), exceto nos solos RQ para o ano de 2009. Os povoamentos florestais implantados no ano de 1987 totalizaram 159 ha, dos quais 119 ha estabelecidos sobre PBAC em altitudes variando de 105 a 162 $\mathrm{m}$, e PV em relevo suave ondulado a ondulado em altitudes de 128 a $162 \mathrm{~m}$. Para esses solos foi verificado, no ano de 2009, saldo positivo de 27 ha do avanço destes cultivos sobre o campo antrópico, com destaque para o cultivo de Eucalyptus sobre PV com saldo positivo de 18 ha, e cultivo de Pinus sobre PV com 7 ha (Tabela 4).

A implantação de povoamentos florestais, principalmente sobre os PBAC e PV, está atrelada ao desenvolvimento desses solos, posição na paisagem e relevo. O maior saldo temporal dos PV é relacionado à maior profundidade do perfil e melhor drenagem, haja vista que os PBAC apresentam drenagem moderada ou imperfeita, o que os mantêm saturados com água em ambiente anaeróbico em determinados períodos do ano, havendo prejuízo ao desenvolvimento vegetal (STRECK et al., 2008). 
TABELA 4: Áreas mensuradas a partir dos cruzamentos entre os planos de informação: solo e cobertura vegetal para os anos de 1987 e 2009.

TABLE 4: Measured areas from the crossings between the layers: soil and vegetation for the years 1987 and 2009.

\begin{tabular}{|c|c|c|c|c|}
\hline 1987 & Área (ha) & 2009 & Área (ha) & Saldo (ha) \\
\hline Agricultura $\times$ PV & 5,0 & Agricultura $\times \mathrm{PV}$ & 0 & $-5,0$ \\
\hline Cultivo de Eucalyptus x RY & 1,0 & Cultivo de Eucalyptus $\times \mathrm{RY}$ & 2,0 & 1,0 \\
\hline Cultivo de Eucalyptus x RQ & 3,0 & Cultivo de Eucalyptus x RQ & 4,0 & 2,0 \\
\hline Cultivo de Eucalyptus x HGP & 5,0 & Cultivo de Eucalyptus x HGP & 6,0 & 1,0 \\
\hline Cultivo de Eucalyptus x PBAC & 39,0 & Cultivo de Eucalyptus x PBAC & 41,0 & 2,0 \\
\hline Cultivo de Eucalyptus x PV & 31,0 & Cultivo de Eucalyptus x PV & 49,0 & 18,0 \\
\hline Cultivo de Eucalyptus x PVA & 5,0 & Cultivo de Eucalyptus x PVA & 6,0 & 1,0 \\
\hline Cultivo de Eucalyptus x RL & 4,0 & Cultivo de Eucalyptus x RL & 10,0 & 6,0 \\
\hline Cultivo de Eucalyptus x TR & 4,0 & Cultivo de Eucalyptus x TR & 3,0 & $-1,0$ \\
\hline Cultivos florestais diversos $\mathrm{x}$ PBAC & 6,0 & Cultivos florestais diversos $\mathrm{x}$ PBAC & 6,0 & 0,0 \\
\hline Cultivos florestais diversos $\mathrm{x} P \mathrm{PV}$ & 22,0 & Cultivos florestais diversos $\mathrm{x}$ PV & 22,0 & 0,0 \\
\hline Cultivos florestais diversos $\mathrm{x}$ PVA & 1,0 & Cultivos florestais diversos $\mathrm{x}$ PVA & 1,0 & 0,0 \\
\hline Cultivos florestais diversos $x \mathrm{RL}$ & 4,0 & Cultivos florestais diversos $\mathrm{x} R \mathrm{~L}$ & 4,0 & 0,0 \\
\hline Floresta nativa $\mathrm{x} R \mathrm{R}$ & 2,0 & Floresta nativa $\times \mathrm{RY}$ & 6,0 & 4,0 \\
\hline Floresta nativa $\times \mathrm{RQ}$ & 2,0 & Floresta nativa $\mathrm{x} R \mathrm{Q}$ & 4,0 & 2,0 \\
\hline Floresta nativa $\mathrm{x}$ HGP & 6,0 & Floresta nativa $\mathrm{x}$ HGP & 14,0 & 8,0 \\
\hline Floresta nativa $\mathrm{x} P B C A$ & 3,0 & Floresta nativa $\mathrm{x}$ PBCA & 32,0 & 29,0 \\
\hline Floresta nativa $\mathrm{x}$ PV & 4,0 & Floresta nativa $\mathrm{x}$ PV & 49,0 & 45,0 \\
\hline Floresta nativa $\mathrm{x}$ PVA & 2,0 & Floresta nativa $\mathrm{x}$ PVA & 9,0 & 7,0 \\
\hline Floresta nativa $\mathrm{x} R$ & 10,0 & Floresta nativa $\mathrm{x}$ RL & 12,0 & 2,0 \\
\hline Floresta nativa $\mathrm{x} R \mathrm{RR}$ & 4,0 & Floresta nativa $\mathrm{x} R \mathrm{R}$ & 9,0 & 5,0 \\
\hline Floresta nativa $\mathrm{x}$ TR & 1,0 & Floresta nativa xTR & 3,0 & 2,0 \\
\hline Cultivo de Pinus x RY & 3,0 & Cultivo de Pinus x RY & 4 & 1,0 \\
\hline Cultivo de Pinus x RQ & 0,0 & Cultivo de Pinus x RQ & 7 & 7,0 \\
\hline Cultivo de Pinus x HGP & 2,0 & Cultivo de Pinus x HGP & 5 & 3,0 \\
\hline Cultivo de Pinus $\mathrm{x}$ PBAC & 12,0 & Cultivo de Pinus $\mathrm{x}$ PBAC & 12 & 0,0 \\
\hline Cultivo de Pinus x PV & 9,0 & Cultivo de Pinus x PV & 16 & 7,0 \\
\hline Cultivo de Pinus x PVA & 5,0 & Cultivo de Pinus x PVA & 4 & $-1,0$ \\
\hline Cultivo de Pinus x RL & 3,0 & Cultivo de Pinus x RL & 9 & 6,0 \\
\hline Cultivo de Pinus x RR & 0,0 & Cultivo de Pinus x RR & 10 & 10,0 \\
\hline Campo antrópico $\mathrm{x} R Y$ & 6,00 & Campo antrópico $\mathrm{x}$ RY & 0,00 & $-6,00$ \\
\hline Campo antrópico $\mathrm{x} R \mathrm{R}$ & 13,00 & Campo antrópico x RQ & 2,00 & $-11,00$ \\
\hline Campo antrópico x HGP & 38 & Campo antrópico x HGP & 27 & $-11,00$ \\
\hline Campo antrópico x PBAC & 65 & Campo antrópico x PBAC & 26 & $-39,00$ \\
\hline Campo antrópico x PV & 127 & Campo antrópico x PV & 54 & $-73,00$ \\
\hline Campo antrópico x PVA & 29 & Campo antrópico x PVA & 22 & $-7,00$ \\
\hline Campo antrópico $\mathrm{x}$ RL & 22,00 & Campo antrópico $\mathrm{x}$ RL & 9,00 & $-13,00$ \\
\hline
\end{tabular}

Continua... 
TABELA 4: Continuação ...

TABLE 4: Continued ...

\begin{tabular}{lcccc}
\hline 1987 & Área (ha) & 2009 & Área (ha) & Saldo (ha) \\
\hline Campo antrópico x RR & 16 & Campo antrópico x RR & 1 & $-15,00$ \\
Campo antrópico x RT & 4 & Campo antrópico x RT & 2 & $-2,00$ \\
\hline
\end{tabular}

Em contraponto ao avanço dos povoamentos sobre os solos PBAC e PV, para o ano de 2009 também houve saldo positivo de 10 ha de Pinus sobre RR (Tabela 4). O sucesso deste povoamento deve-se à ausência de intervenções de manejo neste período e às características das espécies deste gênero botânico, as quais apresentam, na sua grande maioria, elevada produção de pequenas sementes, o que facilita a dispersão anemocórica a longas distâncias, viabilidade de sementes por longos períodos no solo, floração e frutificação mais prolongada, alto potencial reprodutivo por brotação, pioneirismo, alelopatia e ausência de inimigos naturais (ZILLER; GALVÃO, 2001; GROTKOPP et al., 2002).

Avaliando as classes de solos marginais e o pedoambiente deste povoamento, seu sucesso de seu efetivo estabelecimento preferencial em solos do tipo RR está ligado à baixa fertilidade característica do NQ e a fraca ou inexistente coesão entre seus agregados (STRECK et al., 2008), enquanto o GX apresenta caráter hidromórfico o que dificulta $\mathrm{o}$ crescimento vegetal. Comparando com o solo RL, o solo RR apresenta melhores condições para o desenvolvimento radicular, em função da presença de material alterado o que, frequentemente, confere maior fraturamento do material de origem (PEDRON, 2007), favorecendo a exploração do perfil do solo pelas raízes.

Conflitos de uso do solo por implantação de povoamentos florestais foram observados em solos GX e RL, aptos para preservação (STRECK et al., 2008), tendo os GX com cultivos de Eucalyptus saldo positivo de 1 ha e com cultivo de Pinus saldo positivo de 3 ha. Em RL o saldo temporal positivo de cultivos de Eucalyptus foi de 6 ha, mesmo valor observado para os cultivos de Pinus (Tabela 4).

A floresta nativa apresentou variação temporal positiva para todas as classes de solo, com destaque para o seu estabelecimento sobre PV com 45 ha e PBAC com 29 ha. É clara a relação desta fitofisionomia com o relevo e a classe de solo, devido à consequente variação da dinâmica da água no solo, nutrientes e textura (Tabela 4), além da alteração na forma de exploração da terra.
A partir do exposto, sugere-se para a realização de estudos futuros a utilização do receptor do GNSS/RTK (MONICO, 2008) ou de imagens geradas por LIDAR (JENSEN, 2009) no levantamento planialtimétrico das áreas. A caracterização dos solos e descrição dos processos correntes no pedoambiente deve passar pela aplicação de técnicas de mapeamento digital de solos (MCBRATNEY et al., 2003). Por fim, a aplicação de rotinas de modelagem da paisagem pode contribuir com a simulação de cenários de ocupação do solo (SOARES-FILHO et al., 2002), proporcionando subsídios para a gestão integrada das terras.

\section{CONCLUSÕES}

Há um caráter transitório nos componentes da paisagem, entre o Rebordo do Planalto SulRiograndense e a Depressão Central do Rio Grande do Sul, com uma descaracterização das fitofisionomias naturais;

Foram registrados conflitos de uso do solo, pela implantação de cultivos florestais em terras sob GX e RL, aptas para preservação permanente;

O relevo e a gênese dos solos foram condicionantes para o desenvolvimento fitofisionômico;

Em 22 anos houve expansão dos cultivos de Eucalyptus e Pinus, e da floresta nativa sobre o campo antrópico, principalmente nas terras com Argissolos Bruno-Acinzentados e Argissolos Vermelhos.

\section{REFERÊNCIAS BIBLIOGRÁFICAS}

ABRÃO, P. U. R.; GIANLUPPI, D.; AZOLIN, M. A. D. Levantamento detalhado dos solos da estação experimental de silvicultura de Santa Maria. Porto Alegre: IPRNR, 1988. 75 p.

AGUIRRE, A. Levantamento planimétrico da estação experimental de silvicultura de Santa Maria. Santa Maria: UFSM, 1987.

ANJOS, L. H. et al. Landscape and pedogenesis of na 
Oxisol-Inceptisol-Ultisol sequence in Southeastern Brazil. Soil Sci. Soc. Am. J., v. 62, p.1651-1658, 1998.

APG. ANGIOSPERM PHYLOGENY GROUP. An update of the Angiosperm Phylogeny Group classification for the orders and families of flowering plants: APG III. Botanical Journal of the Linnean Society, v. 161, p. 105-121, 2009.

CLARK, D. B. Los factores edáficos y la distribución de las plantas. In: GUARIGUATTA, M. Ecología y conservación de bosques neotropicales, Cartago: LUR, 2002. p. 193-224.

CONSELHO NACIONAL DO MEIO AMBIENTE (BRASIL). Resoluções do CONAMA vigentes publicadas entre setembro de 1984 e janeiro de 2012. Ministério do Meio Ambiente. Brasília: MMA, 2012.

DEMATTÊ, M. E. S. P. Princípios de paisagismo. Jaboticabal: Funep, 1997. 104 p.

EMBRAPA. Sistema brasileiro de classificação de solos. Rio de Janeiro: Embrapa, 2006. 306 p.

GOOGLE. Google Earth Professional. Versão 4.2.0180.1134 (beta). 2007. Acesso em: 15, jan. 2010.

GROTKOPP, E.; REJMÁNEK, M.; ROST, T. L. Toward a causal explanation of plant invasiveness: seedling growth and life-history strategies of 29 pine (pinus) species. The American Naturalist, v. 159, n. 4, p. 398-419, 2002.

IBGE. Carta Santa Maria SH 22-V-C: Geologia. Escala 1:250.000. 2003.

IBGE. Mapa de vegetação do Brasil. Escala 1:5.000.000. 2004.

IBGE. Manual técnico de pedologia. Rio de Janeiro: IBGE, 2007. 323 p.

JENNY, H. Factors of soil formation: a system of quantitative pedology. New York: McGraw-Hill, $1941.281 \mathrm{p}$.

JENSEN, J. R. Sensoriamento remoto do ambiente: uma perspectiva em recursos terrestres. São José dos Campos: Parêntese, 2009. 598 p

KRAAK, M. J.; ORMELING, F. J. Cartography - visualization of spatial data. Harlow: Longman Publishers, 1996.

LEITE, F. P. Contribuição ao conhecimento fitoecológico do sul do Brasil. Ciência \& Ambiente, Santa Maria, v. 1, n. 24, p. 51-73, 2002.

LUCAS, O. W. R. The design of forest landascapes. New York: Oxford Univ.Press,1991.391 p.

MCBRATNEY, A. B.; MENDONÇA SANTOS, M. L.; MINASNY, B. On digital soil mapping. Geoderma, v. 117, p. 3-52, 2003.
MONICO, J. F. G. Posicionamento pelo GNSS: Descrição, Fundamentos e aplicações. 2. ed. São Paulo: UNESP, 2008. v.1. 476 p.

PEDRON, F. de A. Mineralogia, morfologia e classificação de Neossolos e saprolitos derivados de rochas vulcânicas no Rio Grande do Sul. 2007. 160 f. Tese (Doutorado em Ciência do Solo) Universidade Federal de Santa Maria, Santa Maria, 2007.

PORTO, M. L.; MENEGAT, R. Ecologia da Paisagem: um novo enfoque na gestão dos sistemas da terra e do homem. In: MENEGAT et al. Desenvolvimento Sustentável e gestão ambiental nas cidades: estratégias a partir de Porto Alegre. Porto Alegre: UFRGS, 2004.

QUINE, T. A.; ZHANG, Y. An investigation of spatial variation in soil erosion, soil properties and crop production within an agricultural field in Devon, United Kingdom. Journal of Soil and Water Conservation, v.57, p. 55-65, 2002.

SEMA. Diretrizes ambientais para restauração de matas ciliares. Porto Alegre: SEMA, 2007. 33 p. SCHNEIDER, A. S. A flora naturalizada no Estado do Rio Grande do Sul, Brasil: Herbáceas Subespontâneas. Biociências, v. 15, n. 2, p. 257-268, 2007.

SOARES-FILHO, B. S.; CERQUEIRA, G. C.; PENNACHIN, C. L. DINAMICA. a stochastic cellular automata model designed to simulate the landscape dynamics in an Amazonian colonization frontier. Ecological Modelling, v. 154, p. 217-235, 2002.

STRECK, E. V. et al. Solos do Rio Grande do Sul. Porto Alegre: EMATER/ASCAR 2008. 222 p.

VALERIANO, M. M. Modelo Digital de Elevação com dados SRTM para América do Sul. São José dos Campos: Instituto Nacional de Pesquisas Espaciais, 2004. 72 p.

VIDAL-TORRADO, P.; LEPSCH, I. F. Relações material de origem/solo e pedogênese em uma sequência de solos predominantemente argilosos e latossólicos sobre psamitos na depressão periférica paulista. Revista Brasileira de Ciência do Solo, Viçosa, v. 23, n. 2, p. 357-369, 1999.

YOUNG, R. H.; GREEN, D. R.; COUSINS, S. Landscape ecology and geographic information systems. New York: Taylor \& Francis, 1993. $288 \mathrm{p}$.

ZILLER, S. R.; GALVÃO, F. A degradação da estepe gramíneo-lenhosa no Paraná por contaminação biológica de Pinus elliottii e Pinus taeda. Floresta, Curitiba, v. 32, n. 1, p. 42-47, 2001. 